\title{
PARENTING STYLES AS DETERMINANT OF SEXUAL BEHAVIOUR OF IN-SCHOOL ADOLESCENTS IN SOUTH EAST NIGERIA
}

\author{
Chigbu, Eberechukwu Francisca, \\ Ofojebe, Edna Nkechi, \\ Grace Chinyere Nnadi, \\ Uzoekwe, H. E., \\ Mokwelu, Blessing Obianuju ${ }^{\mathrm{i}}$ \\ PhD, Department of Guidance and Counselling, \\ Nnamdi Azikiwe University, \\ Awka, Nigeria
}

\begin{abstract}
:
This study examined the relationship between parenting style and sexual behaviour of in-school adolescents in the South East Zone of Nigeria. The population of this study comprised 137, 095 in-school adolescents in senior secondary II in public secondary schools. The sample of the study was 1200 senior secondary II in-school adolescents. Three research questions and one hypothesis were formulated for the study and the study adopted a correlation survey design. Two instruments, namely: Parenting Style Questionnaire (PSQ) with a reliability coefficient of 0.66; and Sexual Behaviour Questionnaire (SBQ) with a reliability coefficient of 0.78 were developed by the researcher and used for data collection in the study. The research questions in the study were answered using mean, standard deviation, simple regression analysis while t-test and multiple regression analysis was used to test the hypotheses at 0.05 level of significance. The result obtained indicated that the parenting styles to which in-school adolescents were exposed are authoritative, authoritarian and permissive. In-school adolescents' sexual behaviour in South East Nigeria are an attraction to their opposite sex and enjoying sexual intercourse under the influence of alcohol, among others; There exists a direct positive relationship between parenting styles and sexual behaviour of adolescents and a weak variation in sexual behaviour of adolescents is attributed to parenting style; inference drawn from hypothesis one indicated that parenting style has no significant relationship with the sexual behaviour of in-school adolescents. Based on the findings, the researcher recommended among others, that more counsellors should be employed, retained and empowered to help in-school adolescents regulate their engagement with peers and sexual behaviour.
\end{abstract}

iCorrespondence: email ef.chigbu@unizik.edu.ng; en.ofojebe@unizik.edu.ng; chyco4real@yahoo.com; efeyaduhelen@gmail.com; ob.mokwelu@unizik.edu.ng 
Keywords: parenting styles, determinant of sexual behaviour, in-school adolescents

\section{Introduction}

\subsection{Background of the Study}

The parents may exert a far-reaching influence on human behaviour. The co-mingling of the variables has attracted the interest of scholars and researches across the board, with the intent of ascertaining the extent to which they affect behavioral outcomes. The factor (parenting styles) present study is investigated in relation to their likely influence on inschool adolescents' sexual behaviour.

However, sexual behaviour practiced by in-school adolescents is a norm contrary to societal ethics and values. Sexual behaviour simply means the way and manner individuals react or conduct themselves towards everything that has to do with sexual intercourse (Nwagbo and Ubachukwu, 2001). Udadi (2007) opined that sexual behaviour may be leading to multiple sexual intercourses, prostitution, and abnormal sexual practice such as homosexuality, lesbianism, premarital, extramarital sexual intercourse and indiscriminate use of a condom. Udadi, also stated that sexual behaviour is a total action of adolescents, in handling their sexual impulses. Sexual behaviour as defined by Omeje, Ekwueme and Omeje, (2013) is all sexual actions and responses related to pleasant feelings. Also, according to Abba and Echodu in Omeje et al. (2013), sexual behaviour is an individual ability to experience or express sexual feelings. However, the definition of sexual behaviour as conceived by Gebhard, (1982) is any activity, solitary between two persons, or in a group that induces sexual arousal. Gebhard went further to stress two major determinants of human sexual behaviours; the inherited sexual response patterns that have evolved as a means of ensuring reproduction and that are a part of each individual's genetic inheritance, and the degree of restraint or other types of influence exerted on the individual by society in the expression of his sexuality.

However sexual behaviour can be used interchangeably with sexual activities or sexual practice. Sexual behaviour may also include conducts and activities which are intended to arouse the interest of another, such as methods used to display behaviour that will attract the partner such as foreplay. From the foregoing, sexual behaviour in the context of this study is all sexual acts displayed by in-school adolescents for sexual gratification.

Sexual behaviours among in-school adolescents are a reality, for instance, a study carried out in Imo State by Utobo, (2002) among male adolescents revealed that 76 percent of the students had heterosexual intercourse. Data from another survey conducted in Enugu state among secondary school girls aged 13-18 years showed that 17 percent of the girls are sexually active and out of these, 35 percent have multiple sexual partners (Onuiwu \& Echefuns, 2004). The outcome of sexual behaviours may make adolescents particularly vulnerable to sexual exploitation and high-risk behaviours. Often the outcome of this behaviour can have adverse consequences such as unplanned 
pregnancies (for the females) and sexually transmitted infections (Umeugokwe, 2005). In agreement with the aforementioned, Udoga (2011) commented on the rate of sexual debut among adolescents in South East Nigeria and the consequences following it which Udoga enumerated as; unwanted pregnancy, sexually transmitted disease (STD), uterine cancer and abortion which usually lead to high rates of mortality. From the foregoing, it is evident that adolescent sexual behaviour culminating in pregnancy and STI's may also occur in South East states of Nigeria.

The indirect complications of sexual behaviour among in-school adolescents include other negative health outcomes such as increased vulnerability to partner violence (social coercion), elevated risk of HIV/AIDS, teen pregnancy, and sexually transmitted diseases (STDs, STI). It can also result in other psychological manifestations such as emotional damage, depression and other risk behaviours such as suicide, high school dropout, low self-esteem and delinquency (Voon et al., 2004). Adolescents are venerable not only to AIDS and other sexually transmitted infections (STIs) but to the indiscriminate display of sexual behaviour. Thus, the belief they have about sex negatively affects the morals and values of society which pose a serious threat to the future of the younger generation.

Adolescence has been defined variously by many authors. According to United Nations Family Planning Association (2007) and World Health Organization (WHO) (2009), an adolescent is a young person between 10-19 years with his or her own views and evolving decision-making capacities. This is often a stage when conflict and tensions arise and adolescents become identified as problematic by parents. An adolescent is also defined by Hornby (2000) as a person growing up from childhood to adulthood (12 or 13years) with drastic changes in the social, emotional and cognitive aspects.

Furthermore, an adolescent has been identified to have some inherent capacities. These capacities have been clearly outlined in Hornby's definition; covering social, emotional, and cognitive aspects. Further, Hornby in an attempt to buttress these changes (social, emotional and cognitive changes) describes them as drastic, which clearly depicts the radical and fundamental nature of such experience and the far-reaching consequences on adolescent behaviour. Aligning to the above conceptualizations, Ufobi (2001) described an adolescent as a boy or a girl who is changing into a young man and woman between the ages of 13 and 19 years. The adolescent is also perceived by Farlex, (2002) as a young person who has undergone puberty but who has not reached full maturity.

Ncheta (2011) supported these views by defining an adolescent as a person behaving in an immature way and who is also at the period of adolescence or teenage. Ncheta, noted that the teenage years bring about many developmental changes, not only physically but also mentally and socially. Adolescents increase their ability to think abstractly and eventually make plans and set long-term goals. The ages which are considered to be part of adolescence vary by cultural and religious beliefs and orientation and this ranges from 13 years up to 19 years, or even earlier in some cases. Deducing from the perspectives of Ncheta (2011), it can be concluded that the central tendency in 
virtually all definitions of the adolescent is the indication of age range from 13-19years, which thereby justifies the adoption of the term teenage in reference to adolescents. Adolescence is usually used interchangeably with youth. These adolescents can also be called young persons and in secondary schools, they are called in-school adolescents. However, in-school adolescents are adolescents in the four walls of secondary school.

There are psychosocial issues that adolescents deal with during their years according to Huebner, Drane \& Valois (2000), these include: establishing an identity, establishing autonomy, (becoming an independent and self-governing person within relationships) and progression from concrete to abstract thought, establishing intimacy and becoming comfortable with one's sexuality. Based on this assertion, adolescents are at the peak of their development. How in-school adolescents are educated and exposed to sexuality will largely determine whether or not they develop a healthy sexual identity. This is because the adolescents' physical and emotional characteristics of adulthood emerge and social, intellectual and spiritual beginning of the early years are sharpened, tested and shaped for the future at this time (Berk, Rawlings \& Williams, 2000). Adolescents go through the puberty stage which is a time in which a child's sexual and physical characteristics mature. It occurs due to hormonal changes. These changes occur according to gender differences, though the changes are not just marked by physical changes, but comprise cognitive, social/emotional and interpersonal changes as well. However, the exact age a child enters puberty depends on a number of factors, such as genes, nutrition, and gender. During puberty, endocrine glands produce hormones that cause bodily changes and the development of secondary sex characteristics.

In females, the ovaries begin to increase production of estrogens and this leads to the manifestation of breast, widening of pelvis and increases in the amount of body fat in hip, thigh and buttocks. Estrogen also induces growth of the uterus, proliferation of the endometrium (endometrial) and the onset of menstruation. Breast development is the main sign that a girl is entering puberty. Before the first menstrual period, a girl will normally have growth of body hair, most prominently underarm and pubic areas, greater development of high muscle behind the femur, widening of hips, increase in height, and/or whitish vaginal secretion and leg hair growth (Oriade, 2012).

In males, the testicles increase the production of testosterone which directly increases the size and mass of muscles, vocal cords, and bones, deepening the voice, and changing the shape of the face and skeleton. The first sign of puberty in boys is an enlargement of both testicles. Afterwards, boys according to Nicholas in Oracle (2012) will normally experience faster growth, especially height, growth of body hair, including underarm, abdominal, chest hair, pubic hair and face (beards), increased shoulder hair, growth of the penis, scrotum (with reddening and folding of the skin) and testes, nocturnal emissions (or wet dreams) and voice changes and acne. In the context of the present study, an adolescent is a teenager going through adolescence and puberty. Furthermore, an adolescent can be viewed as a child that is going through the transitional 
period between puberty and adulthood (13 and 19years). However, these stages occur during the adolescence stage of development.

The adolescence period is a time people are both physically mature enough to reproduce and critically analyze sexual matters cognitively. The question then arises as to whether adolescents positively or negatively analyses sexual matters cognitively. Thus, Winnie (2008) defined adolescence as a transitional stage of development between childhood and adulthood, representing the period of time during which a person experiences a variety of biological changes and encounters a number of emotional issues, thus, this is why this period is termed, the period of storm and stress. Adolescence like youth is a unique period of joy, vigour, opportunities, as well as challenges as the individual, begins to appreciate more vividly phenomena in his or her personal manner (Ikorok in Ozioko, 2005).

Sexuality and sexual desire usually begin to intensify along with the onset of adolescence. Thus, hormonal changes during the period of adolescence bring about a dramatic increase in sexual interest; but whether this dramatic increase in sexual interest results in sexual behaviour is dependent on the individual because among both adolescents and adults sexual interests vary significantly based on individual differences and environmental factors. Adolescence in the context of this study is a period an inschool adolescent experience an upsurge of sexual feelings triggered off by secretions of hormones. It can also be viewed as a transitional phase of growth and development between childhood and adulthood. As it is noted by Anthony (2007), sexual behaviour is a product of both biological and psychosocial forces which involves the formulation of sexual identity, management of sexual feelings, and autonomy. In line with the above assertion, Ciccletti and Rogosch (2002) opined that adolescents' developmental tasks include challenges of identity, autonomy, sexuality, academic functioning, and peer relationships. These biological changes may create challenges in forming identity, ambivalent feelings of independence, questions about conformity and confusion about values which may lead to risky behaviour. Kelly (2001) observed that 70\% of these risky behaviours boil down to sexual behaviour. Coleman and Carter (2005), supported this view by stressing that a good number of adolescents are found on different cybercafés watching pornographic pictures and films on the internet while others are found in risky environments and nightclubs indulging in prostitution. A key period in sexual exploration and development occurs during adolescence. During this time, individuals begin to consider which sexual behaviour is enjoyable, moral and appropriate for their age group (Levay, 2003). But then, whether sexual behaviour is enjoyable, moral or the society highly discourages adolescents from indulging in it.

On the other hand, parents have been identified to have a critical role in the task of inculcating positive (sexual) values in adolescents. Parenting is the emotional climate in which parents raise their children. These emotional climates are usually characterized by different parenting styles (Spera, 2005). Parenting style is defined by Ncheta (2011) as the manner by which parents raise their children which may depend on the parent's level 
of expectations, performance, domains, and attentiveness to rule as well as the style of discipline that the parents utilize to enforce their expectations. Maccobay and Martin (1983) assert that parenting styles capture two important elements of parenting: parental responsiveness and parental demandingness.

Parental responsiveness (also regarded as parental warmth or supportiveness) refers to the extent to which parents intentionally foster individuality, self-reputation and self-assertion by being attuned, supportive and acquiescent to children's special needs and demands (Baumrid, 1991). Baumrid, further stressed that parental demandingness also referred to as behavioural control refers to the claims parents make on children to become integrated into the family, by their maturity, demands, supervision, disciplinary efforts and willingness to confront the child who disobeys. Baumrid (1991) went further to state that each of these parenting styles (authoritarian, authoritative and permissive) reflects different naturally occurring patterns of parental values, practices and behaviours and a distinct balance of responsiveness and demandingness. According to Baumrid (1991), indulgent parents (also referred to as "permissive or nondirective" are more responsive than they are demanding. They are nontraditional and lenient, do not require mature behaviour, allow considerable self-regulation and avoid confrontation. More so, Baumrid asserts that indulgent parents may be further divided into two types: democratic parents, who though lenient, are more conscientious, engaged and committed to the child, and nondirective parents who are laissez-faire, nonchalant and carefree in their attitude towards the affairs of their children.

Authoritarian parents are highly demanding and directive, but not responsive. They are rigid and controlling and they demand a lot from their children without offering warmth or responding to a child's need. They are obedience and status-oriented and expect their orders to be obeyed without explanation. These parents provide a wellordered and structured environment with clearly stated rules. Authoritarian parents can be divided into two types, non-authoritative directives, which are directive but not intrusive or autocratic in their use of power, and authoritarian directives, which are highly intrusive. In expansion to Baumrind parenting style, Maccobay and Martins (1983) added uninvolved parents (uninvolved parenting style) which are low in both responsiveness and demandingness.

One key difference between authoritarian and authoritative parenting is in the dimension of psychological control. Both authoritarian and authoritative parents place high demands on their children and expect their children to behave appropriately and obey parental rules. Authoritarian parents, however, also expect their children to accept their judgments, values and goals without questioning. In contrast, authoritative parents are more open to give and take with their children and make greater use of explanation. They usually set high expectations and unlike the authoritarian, they are responsive to their child's needs, they are flexible, they listen and give advice, they encourage their children to be independent and assisting while also being respectful to others. They rely on reason, not force. 
Several research efforts have been made to provide reasonable answers to the relationship between parenting style and adolescent sexual behaviour. For instance, Howel, Angel, Huebner (2003), postulated in their studies on the relationship between adolescent sexual risk-taking and perceptions of monitoring, communication and parenting style that parental monitoring, communication and parenting style were significant predictors of sexual risk-taking. More so, adolescents with controlling parents showed an increase in adjustment problems and having over-controlling parents was related to a higher risk of pregnancy (Miller, 1998). Also, Kirby (2001) and Miller (1998) in their separate studies, assert that parental connectedness, closeness, supervision, and behavioral monitoring decreased the risk of adolescent pregnancy. Crow (2008) in his study, discovered that when adolescents perceived too much psychological control on the part of parents, they were more likely to have an earlier sexual debut.

However, sometimes, parental monitoring has less effect on the sexual behaviour of adolescents. A study undertaken by Ralph, Clement, Gina, Wingood, Richard, Cataina, Cob, Kathy, Brendak, Susan, Edward, Hook and Reimid (2014) on parental monitoring associated with adolescents' risk behaviour revealed a consistent pattern of sexual risk behaviours with less perceived parental monitoring. A study was also carried out by Kristan and Kassim (2002) on preventing risky sex and adolescent parenthood. Their findings confirm general findings from other researches indicating that parenting is related to whether or not an adolescent engages in risky sex. In contrast, Luberman (2006) in his study on early predictors of sexual behaviour and implications for young adolescents and their parents stresses that exhibiting a particular parenting style without providing specific guidance about the dynamics of adolescents sexuality will be of limited value to adolescents in the area of sexual behaviour.

This relationship between parenting styles and adolescent sexual behaviour has not been established in South East Nigeria. Based on the foregoing view, this study is set to find out if there is any relationship between parenting styles and sexual behaviour of in-school adolescents in South East Nigeria.

Cognizant of the contribution already made by existing studies in seeking to ascertain factors affecting adolescent sexual behaviour and motivated by the need to fill a gap in knowledge, this study is set to ascertain parenting styles as determinants of sexual behaviour of in-school adolescents in South East Nigeria.

\section{Purpose of the Study}

The main purpose of the study is to find out whether parenting styles is a determinant of the sexual behavior of adolescents in South Eastern, Nigeria. Specifically, the study seeks to:

1) Determine the parenting styles of in-school adolescents.

2) Determine sexual behaviour of in-school adolescents. 
3) Determine the relationship between parenting style and sexual behaviour of inschool adolescents.

\subsection{Significance of the Study}

The study has both theoretical and practical significance. Theoretically, this study hinges on Bunmrind theory of parenting style (1967) which emphasizes the elements that could help shape successful parenting: responsive vs. unresponsive and demanding vs. undemanding. The theory also identified three parenting styles, which include authoritative parenting, authoritarian parenting and permissive parenting. The theory is of the premise that differences in parenting styles accounted for the way children functioned socially, emotionally and cognitively. This theory is crucial in this study because it may provide the basis for establishing the link between parenting styles and sexual behaviour of adolescents in South East, Nigeria.

Differential Association theory by Edwin Sutherland (1930) is basically applicable to the study of crime. This theory is of the view that deviant behaviour is learned through close and frequent association with criminal and deviant behaviour patterns, norms, and values. In effect, the behaviour of an individual is influenced and shaped by other individuals they associate with. This theory is of importance to this study because it may provide a link between peer influence and sexual behaviour of in-school adolescents in South East, Nigeria.

Social learning theory by Albert Bandura (1960) is of the premise that a learner's ability to adopt desired behaviour depends on his environment, cognitive and behavioural outcome. It is of the view that people can learn behaviour observationally, through modeling, extraction of information from those observations, and making decisions about the performance of the behaviour. This is of great benefit to this study as it provides insight into how school environment and peer association can be determinants of sexual behaviour of in-school adolescents in South East Nigeria.

Practically, the findings of this study will be beneficial to the following: researchers, adolescents, parents (family), government, guidance/counsellor and society at large.

The findings of this study are considered significant to the extent that it might be a veritable reference material to future researchers with similar research interests. The material will avail them the opportunity to enhance their knowledge of the research ahead of them.

It is also hoped that the finding of this will be beneficial to adolescents in secondary schools. The findings will enhance the understanding of adolescents through sensitization by the public, parents and school counsellors on the risk of engaging in risky sexual behaviour.

The parents would by this study be made to adopt and exhibit a good parenting style, which is based on responsiveness and demandingness rather than adhering to one of it. This parenting style will enhance the positive behavior of an adolescent and not 
exhibit a parenting style that will push the adolescents to peer pressure. Thus, parents would be sensitized to the different parenting styles through parent's forums by the school counselors and resource persons.

Society at large shall in the long run benefit from the outcome of this investigation when it is effectively implemented. The society shall stand to have a decent responsible and healthy status to help in improving the growth and development of the country and also enhance a healthy posterity.

Based on the findings of this study the government may identify the need to organize workshops, seminars, and conferences for parents and teachers to promote the teaching, learning and practice of good parenting styles. These workshops and seminars could be designed to provide in-service training for teachers on how to improve their knowledge about adolescents and the best way to handle them and to elevate their comfort level both in the school and at home, so as to avert pressures from their peers.

The outcome of this study could further sensitize the school counselor and equip him or her to provide more effective counseling and advice to the adolescent, parents and teachers on the best way to avert the risk sexual behaviour of adolescents and the best parenting style to exhibit on adolescents. However, the best parenting style should be anchored on authoritarian, authoritative and permissive.

Based on the recommendation of this study society as a whole may benefit from a long-time solution in improving the existing relationship and responsive parenting style. In the same way, the school environment is expected to witness positive transformation which will now in turn influence the peer groups positively in South Eastern Nigeria.

\subsection{Scope of the Study}

The content scope of this study focuses on the relationship between parenting styles and sexual behavior of adolescents in South East, Nigeria. This study covered different sexual behaviours of adolescents, types of parenting styles, school environment, and peer influence. The geographical scope of this study was limited to in-school adolescents in South Eastern Nigeria.

\subsection{Research Questions}

The research questions that guided this study are as follows.

1) What are the parenting styles of in-school adolescents?

2) What is the sexual behaviour of in-school adolescents?

3) What is the relationship between parenting styles and sexual behaviour of inschool adolescents?

\subsection{Hypotheses}

The following null hypotheses were tested at 0.05 level of significance.

Ho1: There is no significant relationship between parenting style and sexual behaviour of adolescents. 


\section{Method}

\subsection{Design of the Study}

The design of the study was correlation. This design according to Nworgu (2006) seeks to establish the extent of the relationship between two or more variables and also determine the direction and magnitude of such relationship. Nworgu further states that the design also permits the selection of a sample from the population and using the information generated to make inferences or generalizations to the entire population provided the sample exhibits representativeness in the study.

\subsection{Area of the Study}

The study was carried out in South East, Nigeria. South East, Nigeria is made up of five states namely, Anambra, Abia, Ebonyi, Enugu and Imo. The South East, Nigeria, share boundaries with Benue and Cross River State on the East, Delta and Edo States on the west, Rivers and Akwa Ibom State on the south, Kogi and Benue on the North. The area of the study is the Igbo speaking area; they are also dominated by Christians. The majority of the inhabitants are farmers, civil servants, teachers, counselors and students. This area houses many secondary schools.

Personal experience has also shown that most parents in South East Nigeria engage in business adventure thereby leaving the mentoring of the children at the hands of their peer group. Nigerian adolescents like others at the stage of adolescence, desperately search for identity and strive to conform to peer norms and pressure. This directly exposes them to a negative attitude like sexual behaviour. These aforementioned factors motivated the researcher to conduct the study in South East, Nigeria which is the area of the study.

\subsection{Population of the Study}

The population of this study comprised 137,095 in-school adolescents in senior secondary 2 students in the public (state) secondary school in South East Nigeria. The population distribution is as follows: Anambra State $=42,158$, Ebonyi State $=24,520$, Enugu State $=$ 25,149, Abia $=15,987$ and Imo State $=29,281$. (Source: States Post Primary School Management Board 2020/2021).

\subsection{Sample and Sampling Technique}

The sample for this study was 1200 senior secondary II adolescents. The sampling procedure adopted in this study was multi-stage sampling. First, the area was stratified into five strata: Abia, Anambra, Ebonyi, Enugu and Imo states.

However, the researcher randomly drew three states from the strata Ebonyi, Anambra and Enugu. From each of the States randomly selected, one education zone was randomly selected, and in each education zone, two local government areas were also randomly chosen. Again, from each of the randomly selected local governments, two 
secondary schools were selected randomly making it a total of four secondary schools from the two local government areas. This also gave a total of four secondary schools from each of the states drawn and a total of twelve secondary schools from the three states randomly selected. Thus, from six secondary schools selected 120 SS2 students were derived and 80 SS2 were also adopted thereby giving a total sample of 1,200 students.

The choice of this class of students is based on the fact that they are at the prime of their adolescence where sexual behaviour is often exhibited.

\subsection{Instruments for Data Collection}

The instruments for data collection were four. The instruments are Parenting Style Questionnaire (PSQ) and Sexual Behaviour Questionnaire (SBQ). Parenting style Questionnaire (PSQ) was made up of two sections, A and B. A sought information from the respondents on their personal data. Section B contained 53 items of four clusters of A-authoritarian, B-authoritative, C-permissive, and D-neglectful with response mode of strongly Agree (SA) 4, Agree (A) 3, disagree (D) 2, and Strongly Disagree (SA) 1. Sexual Behaviour Questionnaire (SBQ) also contained 20 items on sexual behaviours with a fourpoint response format of strongly Agree (SA), Agree (A), Disagree (D) and strongly Disagree (SD) weighted 4, 3, 2 and 1 respectively.

\subsection{Validation of the Instruments}

The instrument was face validated by three experts, two from the Department of Educational Foundations, and one from the Department of Science Education (Measurement and Evaluation Unit) all from the Faculty of Education, University of Nigeria, Nsukka. These experts looked at the purpose and the specific objectives of the study, research questions, hypotheses, appropriateness of languages and expressions, clarity of statements as well as the relevance of the sections and items on the instruments and the ability to elicit the required information. These experts constructively scrutinized the instruments and made important corrections and useful suggestions that helped to improve the quality of the instruments.

\subsection{Reliability of the Instrument}

To determine the reliability of the instrument, internal consistency reliability was conducted, thirty in-school adolescents from senior secondary school II in Makurdi in Benue State Nigeria which is outside the area of the study were selected and the instruments administered to them to enable the researcher to generate data for computing the reliability index. Internal consistency reliability was calculated using the Cronbach alpha correlation. The rationale for the use of Cronbach alpha was on the basis that the items were not scored right or wrong (dichotomously) but rather were placed on a four-point rating scale of SA, A, D and SD. The analysis of the data yielded reliability 
coefficient indices of 0.66 for the parenting style questionnaire and 0.78 for sexual behaviour questionnaire.

\subsection{Method of Data Collection}

Copies of the instruments were administered to the respondents using the direct delivery and retrieval method. The distributions of the questionnaire to the sampled students were done personally by the researcher with the help of two research assistants. The use of research assistants is to facilitate the distribution and retrieval of the completed copies of the questionnaire. The research assistants were instructed on the objectives of the study.

\subsection{Method of Data Analysis}

Mean and standard deviation were used to analyze research questions 1 and 2 while simple linear regression was used to analyze research questions 3. T-test was used to test hypotheses 1 . In using mean, the real limit of numbers was used whereby 0.00-0.49 indicates strongly disagreed, 1.00-1.49 indicates disagreed, 2.0-2.49 indicates agreed, 3.004.00 indicates strongly agreed.

\section{Results}

The results of this study are presented in line with research questions and hypotheses that were posed and formulated to guide the study. Thereafter, the summary of the findings was presented too.

Research Question One: What are the parenting styles of in-school adolescents?

Table 1A: Mean Ratings of Respondents on the Parenting Styles of In-School Adolescents

\begin{tabular}{|c|c|c|c|c|}
\hline \multirow{2}{*}{$\mathbf{S} / \mathbf{N}$} & \multirow{2}{*}{ Items Statement on Parenting Styles } & \multicolumn{3}{|c|}{$\mathrm{N}=1200$} \\
\hline & & $\overline{\boldsymbol{x}}$ & SD & Dec. \\
\hline & \multicolumn{4}{|l|}{ Cluster 1: Authoritarian } \\
\hline 1. & $\begin{array}{l}\text { When I ask my parent why I should do something he/she } \\
\text { tells me because that is what he/she wants. }\end{array}$ & 3.50 & 0.50 & SA \\
\hline 2. & My parents punish me by taking privileges away from me. & 1.12 & 0.32 & $\mathrm{D}$ \\
\hline 3. & $\begin{array}{l}\text { My parents usually shout at me when they disapprove } \\
\text { of my behaviour. }\end{array}$ & 3.85 & 0.43 & SA \\
\hline 4. & My parents believe I should not have secrets. & 3.53 & 0.50 & SA \\
\hline 5. & $\begin{array}{l}\text { My parents usually spank me when they do not like what } \\
\text { I do or say. }\end{array}$ & 3.44 & 0.58 & SA \\
\hline 6. & $\begin{array}{l}\text { My parents expect me to accept their values and goals without } \\
\text { inhibition. }\end{array}$ & 3.43 & 0.58 & SA \\
\hline 7. & $\begin{array}{l}\text { My parents use threats as a form of punishment with little or no } \\
\text { justification. }\end{array}$ & 3.45 & 0.55 & SA \\
\hline 8. & My parents punish me by withholding emotional expression. & 3.42 & 0.58 & SA \\
\hline 9. & My parents openly criticize me when my behaviour does not meet & 3.42 & 0.58 & SA \\
\hline
\end{tabular}




\begin{tabular}{|c|l|c|c|c|}
\hline \hline & their expectation. & & & \\
\hline 10. & My parents always shout at me in anger towards me. & 3.50 & 0.50 & SA \\
\hline 11. & $\begin{array}{l}\text { My parents always expect me to accept their judgments } \\
\text { without questioning. }\end{array}$ & 3.46 & 0.56 & SA \\
\hline 12. & My parents always supervise all my actions. & 3.46 & 0.56 & SA \\
\hline 13. & My parents do not allow me to make my choice. & 2.00 & 0.25 & A \\
\hline 14. & $\begin{array}{l}\text { My parents feel is only through punishment that a child could } \\
\text { be corrected. }\end{array}$ & 3.54 & 0.50 & SA \\
\hline 15. & My parents like to choose my friend for me. & 3.53 & 0.50 & SA \\
\hline & Grand Mean & $\mathbf{3 . 2 4}$ & $\mathbf{0 . 5 0}$ & SA \\
\hline \hline
\end{tabular}

$\overline{\boldsymbol{X}}$ = Mean; SD = Standard Deviation; SA = Strongly Agreed; A = Agreed; D = Disagreed; SD = Strongly Disagreed

The result in Table 1A shows the mean ratings of respondents parenting styles of inschool adolescents. The mean ratings and standard deviation of respondents on item numbers $1,3-12,14$ and 15 ranging between 3.50 to 3.85 and 0.43 to 0.50 respectively, revealed that the respondents strongly agreed (SA) on the items highlighted above as a parenting style of in-school adolescents. Meanwhile, the mean ratings on item number 13 with a mean of 2.00 and standard deviation of 0.25 respectively revealed that the respondents agreed with the item highlighted above. Furthermore, the mean rating of 1.12 and standard deviation of 0.32 for item 2 revealed that the respondents disagreed with the item highlighted as authoritarian parenting style. Based on the analysis of the table where a grand mean score of 3.24 and standard deviation of 0.50 was reached. It revealed that the respondents strongly agreed with the items in Table 1A as the authoritarian parenting style of in-school adolescents in South East Nigeria.

Table 1B: Mean Ratings of Respondents on the Parenting Styles of In-School Adolescents

\begin{tabular}{|c|l|c|c|c|}
\hline \multirow{2}{*}{ S/N } & \multirow{2}{*}{ Items Statement on Parenting Styles } & \multicolumn{3}{|c|}{ N=1200 } \\
\cline { 3 - 5 } & \multicolumn{2}{|c|}{$\bar{x}$} & SD & Dec. \\
\hline & Cluster 2: Authoritative & 3.08 & 0.26 & SA \\
\hline 1. & My parents are responsive to my feelings. & 3.50 & 0.50 & SA \\
\hline 2. & $\begin{array}{l}\text { My parents do take my wishes into consideration before } \\
\text { asking me to do something. }\end{array}$ & 3.50 & 0.50 & SA \\
\hline 3. & $\begin{array}{l}\text { My good/bad behaviour is being expressed by my parents } \\
\text { through their behaviour. }\end{array}$ & 4.00 & 0.00 & SA \\
\hline 4. & My parents usually encourage me to express my feelings positively. & 3.50 & 0.50 & SA \\
\hline 5. & $\begin{array}{l}\text { I am being encouraged to speak my mind even If it disagrees with } \\
\text { my parents' view. }\end{array}$ & 4.00 & 0.00 & SA \\
\hline 6. & My parents always encourage me to be independent. & 3.50 & 0.50 & SA \\
\hline 7. & Whenever am upset, my parents provide comfort for me. & 4.00 & 0.00 & SA \\
\hline 8. & My parents do compliment me when I do the right thing. & 4.00 & 0.00 & SA \\
\hline 9. & $\begin{array}{l}\text { My mother and father always consider my opinion when they } \\
\text { make plans for the family. }\end{array}$ & 3.50 & 0.50 & SA \\
\hline 10. & My parents respect my opinion and encourage me to express them. & 3.97 & 0.17 & SA \\
\hline 11. & My parents treat me as an equal member of the family. & & \\
\hline
\end{tabular}




\begin{tabular}{|c|l|c|c|c|}
\hline \hline 12. & They usually educate me to be respectful to others & 3.90 & 0.31 & SA \\
\hline 13. & $\begin{array}{l}\text { My parents always have warm and intimate times together } \\
\text { with family. }\end{array}$ & 3.50 & 0.50 & SA \\
\hline 14. & My parents expect me to handle my problems by myself. & 1.00 & 0.00 & D \\
\hline & Grand Mean & $\mathbf{3 . 5 0}$ & $\mathbf{0 . 2 7}$ & SA \\
\hline \hline
\end{tabular}

$\overline{\overline{\boldsymbol{X}}}$ = Mean; SD = Standard Dev.; SA = Strongly Agreed; A = Agreed; SD = Strongly Disagreed

The result in Table 1B shows the mean ratings of respondents parenting styles of inschool adolescents. The mean ratings and standard deviation of respondents on item numbers 2-13, ranging between 3.50 to 4.00 and 0.00 to 0.50 respectively, revealed that the respondents strongly agreed (SA) on the items highlighted above as a parenting style of in-school adolescents. However, respondents agree and strongly disagree on items 1 and 14, with the mean ratings and standard deviation values of 3.08, 1.00 and $0.26,0.00$ respectively. On the grand mean score of 3.50 with a standard deviation value of 0.27 respondents strongly agreed (SA) on items in Table $1 \mathrm{~B}$ as the authoritative parenting styles of in-school adolescents in South East Nigeria.

Table 1C: Mean Ratings of Respondents on the Parenting Styles of In-School Adolescents

\begin{tabular}{|c|c|c|c|c|}
\hline \multirow[b]{2}{*}{$\mathbf{S} / \mathbf{N}$} & \multirow{2}{*}{ Items Statement on Parenting Styles } & \multicolumn{3}{|c|}{$\mathrm{N}=\mathbf{1 2 0 0}$} \\
\hline & & $\bar{x}$ & SD & Dec. \\
\hline & Cluster 3: Permissive & & & \\
\hline 1. & I like my parents because they are very friendly to me. & 3.50 & 0.50 & SA \\
\hline 2. & My parents appear unaware on how to solve my problems & 1.06 & 0.23 & $\mathrm{D}$ \\
\hline 3. & My parents bribe me with rewards to bring about compliance. & 1.54 & 0.50 & $\mathrm{D}$ \\
\hline 4. & My parents do bribe me with reward to obtain compliance. & 1.52 & 0.50 & $\mathrm{D}$ \\
\hline 5. & My parents usually ignore me when I misbehaved. & 3.45 & 0.62 & SA \\
\hline 6. & $\begin{array}{l}\text { Parents withhold scolding and/or criticism even when a child } \\
\text { act contrary to our wishes. }\end{array}$ & 3.49 & 0.50 & SA \\
\hline 7. & My parents find it difficult to discipline me when I misbehave & 3.48 & 0.50 & SA \\
\hline 8. & $\begin{array}{l}\text { My parents are afraid that disciplining me for misbehavior } \\
\text { will cause me not to like them. }\end{array}$ & 1.49 & 0.50 & $\mathrm{D}$ \\
\hline 9. & I am being pampered by my parents. & 2.26 & 0.82 & A \\
\hline 10. & My parents scolded me each time I misbehave. & 2.28 & 1.29 & A \\
\hline 11. & Grand Mean & 2.41 & 0.60 & $\mathbf{A}$ \\
\hline
\end{tabular}

$\overline{\overline{\boldsymbol{X}}}$ = Mean; SD = Standard Deviation; SA = Strongly Agreed; A = Agreed; D = Disagreed; SD = Strongly Disagreed

The result in Table 1C shows the mean ratings of respondents parenting styles of inschool adolescents. The mean ratings and standard deviation of respondents on item numbers 1, 5-7 ranging between 3.45 to 3.50 and 0.50 to 0.62 respectively, revealed that the respondents strongly agreed (SA) on the items highlighted above as a parenting style of in-school adolescents. However, the mean ratings of items numbers 9 and 10 with mean of 2,26 and 2.28 and standard deviation of 0.82 and 1.29 respectively revealed that the respondents agreed with the item highlighted above. Meanwhile, the mean ratings 
on item numbers 2-4, 8 which ranges between 1.06-1.54, with corresponding standard deviation values of 0.23 to 1.50, revealed that respondents disagreed (D) and Agree on the item highlighted above as a parenting style of in-school adolescents. Based on the grand mean score of 2.41 with a standard deviation value of 0.60 respondents agreed on items in table $1 \mathrm{C}$ as the parenting styles of in-school adolescents in South East Nigeria.

Table 1D: Mean Ratings of Respondents on the Parenting Styles of In-School Adolescents

\begin{tabular}{|c|c|c|c|c|}
\hline \multirow{2}{*}{$\mathbf{S} / \mathbf{N}$} & \multirow{2}{*}{ Items Statement on Parenting Styles } & \multicolumn{3}{|c|}{$\mathrm{N}=\mathbf{1 2 0 0}$} \\
\hline & & $\bar{x}$ & SD & Dec. \\
\hline & \multicolumn{4}{|l|}{ Cluster 4: Neglectful/Uninvolved Parenting } \\
\hline 1. & My parents always neglect my needs & 1.10 & 0.30 & $\mathrm{D}$ \\
\hline 2. & My parents are unable to encourage, teach me what I do not know. & 1.56 & 0.58 & $\mathrm{D}$ \\
\hline 3. & My parents have few or no expectations on demands for behaviour. & 1.53 & 0.56 & $\mathrm{D}$ \\
\hline 4. & $\begin{array}{l}\text { My parents don't attend school events example, parents teachers } \\
\text { association. }\end{array}$ & 1.50 & 0.50 & $\mathrm{D}$ \\
\hline 5. & My parents intentionally avoid me. & 2.50 & 0.50 & A \\
\hline 6. & $\begin{array}{l}\text { My parents are often too overwhelmed with problems and this } \\
\text { makes them not to attend to my problems. }\end{array}$ & 1.57 & 0.60 & $\mathrm{D}$ \\
\hline 7. & My parents do not encourage me for better understanding. & 1.53 & 0.50 & $\mathrm{D}$ \\
\hline 8. & My parents are emotionally distant from me. & 1.07 & 0.25 & $\mathrm{D}$ \\
\hline 9. & Parents ignore their child emotions/problems. & 1.50 & 0.50 & $\mathrm{D}$ \\
\hline 10. & My parents offer little or no supervision to what I do. & 1.52 & 0.50 & $\mathrm{D}$ \\
\hline 11. & My parents show little warmth, love and affection towards me. & 2.53 & 0.50 & A \\
\hline 12. & $\begin{array}{l}\text { My parents keep their distance from me because they are usually } \\
\text { preoccupied with their own concerns. }\end{array}$ & 2.00 & 0.00 & A \\
\hline 13. & My parents hardly supervise me. & 1.53 & 0.05 & $\mathrm{D}$ \\
\hline 14. & $\begin{array}{l}\text { My parents have difficulty in establishing and maintaining } \\
\text { relationships with me. }\end{array}$ & 1.53 & 0.50 & $\mathrm{D}$ \\
\hline & Grand Mean & 1.64 & 0.42 & D \\
\hline
\end{tabular}

$\overline{\overline{\boldsymbol{X}}}$ = Mean; SD = Standard Deviation; A = Agreed; $\mathrm{D}=$ Disagreed; SD = Strongly Disagreed

The result in Table 1D shows the mean ratings of respondents parenting styles of inschool adolescents. The mean ratings and standard deviation of respondents on item numbers $1-4,6-10$ and 13-14 ranging between 1.07 to 1.57 and 0.05 to 0.60 respectively, revealed that the respondents disagreed (D) on the items highlighted above as neglectful parenting style of in-school adolescents. However, respondents agreed on items 5, 11 and 12 with the mean ratings and standard deviation values of 2.50, 2.53, 2.00 and 0.50, 0.50 and 0.00 respectively. Based on the grand mean score of 1.64 with a standard deviation value of 0.42 respondents disagreed on items in table $1 \mathrm{D}$ as the parenting styles of inschool adolescents in South East Nigeria. 
Research Question Two: What are the sexual behaviours of in-school adolescents?

Table 4: Mean Ratings of Respondents on the Sexual Behaviour of In-School Adolescents

\begin{tabular}{|c|c|c|c|c|}
\hline \multirow{2}{*}{$\mathbf{S} / \mathbf{N}$} & \multirow{2}{*}{ Item Statements on Sexual Behaviour } & \multicolumn{3}{|c|}{$\mathrm{N}=\mathbf{1 2 0 0}$} \\
\hline & & $\overline{\boldsymbol{x}}$ & SD & Dec. \\
\hline 1. & $\begin{array}{l}\text { I am always attracted to my opposite sex during an erotic discussion } \\
\text { with him. }\end{array}$ & 3.46 & 0.69 & SA \\
\hline 2 & I enjoy having sexual intercourse under the influence of alcohol. & 3.37 & 0.70 & SA \\
\hline 3 & I often have sexual intercourse. & 3.44 & 0.70 & SA \\
\hline 4 & Oral sex is more enjoyable than sexual intercourse. & 3.43 & 0.67 & SA \\
\hline 5 & Romance increases my sexual urge. & 3.43 & 0.70 & SA \\
\hline 6 & I am always sexually active if I take a sexual stimulating drug. & 3.48 & 0.65 & SA \\
\hline 7 & I enjoy anal sex more than oral sex. & 2.14 & 0.80 & A \\
\hline 8 & I enjoy having sex with the same sex partner more than the opposite sex. & 2.16 & 0.77 & A \\
\hline 9 & Touching a partner's breast stimulates me. & 3.48 & 0.64 & A \\
\hline 10 & I often use contraceptives during intercourse. & 3.44 & 0.68 & A \\
\hline 11. & I enjoy having sexual intercourse with more than one person at a time. & 2.03 & 0.96 & A \\
\hline 12. & I often reach organism through having sex with the same sex partner. & 2.01 & 0.81 & A \\
\hline 13. & I enjoy using sex toys to satisfy my urge. & 3.45 & 0.67 & $\mathrm{~A}$ \\
\hline 14. & I get stimulated quickly when my breast is been romanced. & 3.48 & 0.69 & A \\
\hline 15 & $\begin{array}{l}\text { I like watching pornographic films because it stimulates my sexual } \\
\text { organs. }\end{array}$ & 3.49 & 0.68 & A \\
\hline 16 & I love to engage into multiple sexual relationships. & 1.98 & 1.04 & $\mathrm{D}$ \\
\hline 17 & Having sex with more than one person is ideal for youths. & 1.92 & 0.85 & $\mathrm{D}$ \\
\hline 18 & Having sex with members of the same sex is the in thing. & 2.02 & 0.90 & A \\
\hline 19 & Adolescent enjoy masturbation. & 3.36 & 0.89 & SA \\
\hline \multirow[t]{2}{*}{20} & I hate having sexual intercourse because it irritates me. & 2.02 & 0.90 & A \\
\hline & Grand Mean & 2.88 & 0.77 & A \\
\hline
\end{tabular}

$\overline{\boldsymbol{X}}=$ Mean; SD = Standard Deviation; SA = Strongly Agreed; A = Agreed; D = Disagreed; SD = Strongly Disagreed

The result in Table 4 shows the mean ratings of respondents on what is the sexual behaviour of in-school adolescents. The mean ratings and standard deviation of respondents on items 1-6 and 19 ranging between 3.36-3.48 and 0.65-0.89 respectively revealed that respondents strongly agreed (SA) on the items highlighted above as the sexual behaviour of in-school adolescents. Meanwhile, the mean ratings and standard deviation of respondents on item numbers 7-15, 18 and 20 ranging between 2.01-3.49 and 0.64-0.96respectively, revealed that respondents agreed (A) on the items highlighted above as the sexual behaviour of in-school adolescents. However, on item numbers 16 and 17 , the mean ratings and standard deviation of respondents ranges from 1.92-1.98 and 0.85-1.04 respectively. This shows that respondents disagreed (D) on the items highlighted above as the sexual behaviour of in-school adolescents. Meanwhile, on the grand mean score of 2.88 with a standard deviation value of 0.77 respondents Strongly agreed (A) on items in table 4 as the sexual behaviour of in-school adolescents in South East Nigeria. 
Research Question Three: What is the relationship between parenting styles and sexual behaviour of adolescents?

Table 5: Simple regression Analysis of parenting styles and sexual behaviour of adolescents

\begin{tabular}{|c|c|c|c|c|}
\hline Model & R & R Square & Adjusted R Square & Std. Error of the Estimate \\
\hline 1 & $0.232^{\mathrm{a}}$ & 0.054 & 0.064 & 0.1992263 \\
\hline
\end{tabular}

a. Predictors: (Constant), Parent style.

To answer this research question, the scores from the responses of the students on parenting styles were correlated with their responses on the sexual behaviour of adolescents. The result in Table 5 shows that the correlation coefficient obtained was 0.23. This means that there exists a direct positive relationship between parenting styles and the sexual behaviour of adolescents. Table 5 also shows that the coefficient of determination $\left(\mathrm{R}^{2}\right)$ associated with the correlation coefficient of 0.23 is 0.05 . Furthermore, $6.4 \%(0.064 \times 100)$ of variation in sexual behaviour is accounted for by parenting styles while $93.6 \%$ by other factors.

Ho1: There is no significant relationship between parenting style and sexual behaviour of adolescents.

Table 6: Special t-test Analysis of Parenting Style and Sexual Behaviour of Adolescents

\begin{tabular}{|l|l|c|c|c|c|c|}
\hline \multirow{2}{*}{ Model } & \multicolumn{2}{|c|}{$\begin{array}{c}\text { Unstandardized } \\
\text { Coefficients }\end{array}$} & $\begin{array}{c}\text { Standardized } \\
\text { Coefficients }\end{array}$ & \multirow{2}{*}{ t } & \multirow{2}{*}{ Sig. } \\
\cline { 3 - 7 } \multicolumn{2}{|l|}{} & B & Std. Error & Beta & & \\
\hline \multirow{2}{*}{1} & (Constant) & 2.690 & .128 & & 20.982 & .000 \\
\cline { 2 - 7 } & Parental Style & .062 & .042 & .043 & 1.481 & .139 \\
\hline
\end{tabular}

In order to test hypothesis 1, regression analysis was used. The result in Table 6 shows the $t$-value of 1.481 with an associated exact probability value of 0.139 was calculated. This probability value of 0.139 was compared with 0.05 set as a level of significance for testing the hypothesis and it was found not significant because 0.139 is greater than 0.05 . The null hypothesis which stated that; there is no significant relationship between parenting style and sexual behaviour of adolescents was not rejected. The inference drawn was that parenting style has no significant relationship with the sexual behaviour of in-school adolescents in South East Nigeria. Although there existed a direct positive relationship between parenting styles and sexual behaviour of in-school adolescents in South East, Nigeria, the direct positive relationship is not significant, and therefore it may be due to chance.

\section{Summary of the Findings}

The findings of this study revealed the following: 
1. The parenting styles in-school adolescents were exposed to were authoritative, authoritarian and permissive.

2. There existed a direct positive relationship between parenting styles and sexual behaviour of adolescents and a weak variation in sexual behaviour of adolescents is attributed to parenting style.

3. Inference drawn from the hypothesis indicated that parenting styles have no significant relationship with the sexual behaviour of in-school adolescents in South East Nigeria.

\section{Discussion of Findings}

The findings of the study are discussed in line with the research questions and hypotheses that guided the study. They are discussed under the following sub-headings:

1) Constituents of Parenting Styles of In-School Adolescents;

2) Constituents of Sexual Behaviours of In-School Adolescents;

3) Relationship between Parenting Styles and Sexual Behaviour of Adolescents.

\subsection{Constituents of Parenting Styles of In-School Adolescents}

In line with the research question on the parenting styles of in-school adolescents, authoritative, authoritarian and permissive parenting styles constitute the parenting styles of in-school adolescents in South-East, Nigeria. These parenting styles include: my parents being responsive to feelings; my parents do take my wishes into consideration before asking me to do something; my good/bad behaviour is being expressed by my parents through their behaviour; my parents usually encourage me to express my feelings positively; I am being encouraged to speak my mind even if it disagrees with my parents view; my parents always encourage me to be independent; whenever am upset, my parents provide comfort toward me; my parents do compliment me when I do the right thing; my mother and father always consider my opinion when they make plans for the family; my parents respect my opinion and encourage me to express them; my parents treat me as an equal member of the family; they usually educate me to be respectful to others, and my parents always have warm and intimate times together with family.

Furthermore, the following items were agreed (A) upon and these include: when I ask my parent why I should do something he/she tells me because that is what I want, my parents usually shout at me when they disapprove of my behaviour; my parents believe I should not have secrets; my parents usually spank me when they do not like what I do or say; my parents also expect me to accept their values and goals without inhibition; my parents use threats as a form of punishment with little or no justification; my parents punish me by withholding emotional expression; my parents openly criticize me when my behaviour does not meet their expectation; my mother always shouts at me in anger towards me; my parents always expect me to accept their judgments' without 
questioning; my parents always supervise all my actions; my parents feel is only through punishment that a child could be corrected, and my parents like to choose my friend for me.

These findings show the prevalence of authoritative, authoritarian and permissive parenting styles which support the study of Perozzi (2007) on the behaviour of adolescents based on the type of parenting style exhibited by parents but differ because the current study highlighted the constituents of the parenting style while Perozzi study only examines the behaviour of adolescent based on the type of parenting style. Also, the linear regression analyses which revealed that parental monitoring accounted for most of the variance with both drinking variables shows that Perozzi studies only relationship behaviour of adolescents based on the type of parenting style.

The findings are also in-line with Ann, Kofi, Asare, and Akinrinola (2004) who revealed that unmarried adolescents report moderate to high levels of parental monitoring and low levels of parent-child communication about sexual matters. By reference to similarity on the findings of the present study there exist a direct relationship between parenting style and sexual behaviour of an adolescent.

\subsection{Constituents of Sexual Behaviour among In-School Adolescents}

In line with research questions on what constitutes sexual behaviour among in-school adolescents. Respondents from this study agreed that they are attracted by their opposite sex, enjoy having sexual intercourse under the influence of alcohol, enjoy masturbation, watching pornographic films, engaging in foreplay as this increases their sexual urge, and these constitutes sexual behaviour of in-school adolescents in South-East,

The present finding is in an accord with the result of Kasier (2003) which reveals that young people are more concerned about sex and sexual behaviour than any other sexual issues in their lives. Again, adolescents feel great pressure to have sex. The present study is consistent with that of Kasier (2003) in the area of adolescents engaging in sexual behaviour. The present study also stated that adolescents enjoy sexual intercourse which is in agreement with the findings of the study conducted by Onyia (2000) in the area of adolescents having sexual intercourse. Hence, there are differences from the previous study in the area of males and females having unprotected sex which the present study did not indicate.

The present study indicated that adolescence enjoys sexual intercourse. The findings of the present study also concurred with the findings conducted by Beth, Anne, Rex and Kim (2001). The result of the findings indicated that a considerable percentage are initiating sexual activity by early or middle adolescence, with $21 \%$ of adolescent males having engaged in sexual intercourse by age 15 . The present study lends credence to Petard, Courtois, Rusch (2008) who noted that perception of peers is associated with a higher frequency of sexual initiation and commitment, including oral sex. The present study indicated that adolescents enjoy oral sex, hence, the similarity. 
These findings confirm that sexual behaviour is peculiar to the adolescence period since the adolescents start experiencing marked changes in their sexual structure in response to puberty. The period makes the individuals conscious of their sexes, and become attracted to each other, especially opposite sex. Some of them, though not all develop desire and passion for opposite-sex friendship and this push them into engaging in sexual behaviour.

\subsection{Relationship between Parenting Styles and Sexual Behaviour of Adolescents}

In line with research question five, the current findings stated the existence of a direct positive relationship between parenting styles and sexual behaviour of adolescents, and a weak variation in sexual behaviour of adolescents to parenting style. The inference drawn from the hypothesis; parenting style has no significant relationship with the sexual behaviour of in-school adolescents in South East Nigeria. The findings of the present study are in agreement with the study conducted by Sieverding, et al. (2005), which revealed that Parenting style was found to be directly associated with the delay of the first sexual experiences for the adolescent between the age of 15-16years. The present study also concurred with the study conducted by Katty, Lynda, Dashiff, Susan (2002) which revealed that there is a direct relationship between sexual risk-taking and parental monitoring and communication. These adolescents who were closely supervised by their parents had a lower amount of sexual risk-taking than those adolescents who had low amounts of parental monitoring or supervision. They equally indicated that variables of age, gender, and race demonstrated no relationship with sexual risk behaviour. More so, the quality of the parent-adolescent relationship has a significant impact on the development or prevention of risky adolescent health behaviour. The current findings buttressed that of Katty, et al. (2002) as both studies show a direct positive relationship between parenting styles and sexual behaviour of adolescents. The difference in both studies is that Katty, et al.'s study centered on sexual risk-taking by adolescents while the current study is on the sexual behaviour of adolescents.

However, the present findings of the study confirm an opinion expressed by Cherie and Berhania (2015). According to Cherie et al, their findings indicated that parenting styles and practices have a paramount influence on the sexual behaviour of adolescents. Presently, the finding from the current study is in line with a study conducted by Dinorah, (2015). The result shows that environmental factors are related to sexual risk behaviour in adolescents, with the most significant being family relationships.

\section{Conclusions}

From the foregoing discussions based on the results of the study, it was discovered that authoritative, authoritarian and permissive parenting styles are the parenting styles of in-school adolescents in South East Nigeria. Based on the purpose of the study is to find out whether parenting styles is a determinant of the sexual behaviour of adolescents in 
South East Nigeria. The findings statistically stated that there existed a direct positive relationship between parenting styles and sexual behaviour of adolescents and a weak variation in sexual behaviour of adolescents is attributed to parenting style. The inference drawn from hypothesis one indicated that parenting styles have no significant relationship with the sexual behaviour of in-school adolescents in South East Nigeria.

\subsection{Implications of the Findings}

The findings of this study have tremendous implications for the researchers, adolescents, parents (family), government, guidance/counsellor and society at large. These implications are discussed as follows:

1) Since, Authoritative and Authoritarian Parenting styles are the parenting styles used then parents will be able to openly criticize their children when their behaviour does not meet their expectations always. Also, parents will consider their children's opinions when plans are being made for their family.

2) Since, parenting style has a direct positive relationship to sexual behaviour of inschool adolescents; parents should be encouraged through seminars to be careful in the training of their wards by exhibiting the right parenting style.

3) There exists a direct relationship between school environment and sexual behaviour of in-school adolescents, hence, government and school management should provide an enabling environment so as to ensure good conduct among inschool adolescents.

\subsection{Recommendations}

On the basis of the findings of this study, the following recommendations were made with a view to improving the sexual behaviour of in-school adolescents.

1) Teachers and counselors should give the in-school adolescents proper and adequate sexuality education to help them avoid risky sexual behaviour.

2) Parents should not use only one parenting style. Rather, they should use a combination of three types of parenting styles (authoritative, authoritarian and laissez-fair) that would result in an eclectic parenting style. This is because, in the actual sense of a home, there would be a situation where each of the parenting styles would be applied.

3) More school counselors should be employed and retrained through in-service training programmes, capacity building workshops and refresher courses on sexual behaviour counseling.

4) The school authority should print and provide school guidance counselors with adequate materials (furniture for administrative and counseling conveniences; file cabinet for record-keeping, a notice board for information dissemination; logbook; advertisement forms to enlighten students on service in counseling centre, files; counseling records; registration form; request form for counseling interview, case 
report sheet, consultation form, and appointment slip.) to carry out their functions effectively.

5) Religious leaders and community leaders should be co-opted into a committee that will enlighten the in-school adolescence on the disadvantages of engaging in sexual behaviour.

6) Proper and adequate Sexuality education should be incorporated into the secondary school curriculum; this will go a long way in enhancing the scope of inschool adolescents on the best way to avert immorality and sexual behaviour.

7) Parents should also be educated through seminars, and workshops on the best way to train the in-school adolescents knowing full well their challenges.

8) Government should ensure that the school environment becomes friendly. The schools should be operated on very strict rules and regulations.

9) Researchers should develop e-counselling model or cyber-counseling for the modification of risky sexual behaviour among adolescents. This model might be the quickest and most effective method of modifying sexual behaviour arising from engagement in internet communication. This can occur between a counselor and in-school adolescent through email, video conferencing, online chat, messaging, or internet phone.

\subsection{Limitations of the Study}

It is imperative to state here that though the present study provides important clues for future researchers, it is not free from limitations. Like any other report study, some of the responses could have been subjective. Thus, the question of faking on the part of the respondents may not be ruled out. To this end, future researchers that will improve upon the limitation of this present study are urgently needed.

\subsection{Suggestions for Further Studies}

Based on the findings of this study, it became imperative to make the following suggestions for further investigations;

1) Parenting style, peer influence, school environment as determinants of sexual behaviour in North West Nigeria.

2) Effect of Sexual behaviour of adolescents on the academic achievement of secondary school students can also be studied.

3) The study can be replicated using other methods of data analysis and larger samples.

\section{Summary of the Study}

The main purpose of the study was to find out the relationship between parenting styles and sexual behaviour of adolescents in South Eastern zone of Nigeria. To guide the study, eight research questions were posed and Four hypotheses were equally formulated and 
tested at 5\% probability level. A correlational survey research design was adopted for this study. This study was carried out in public (state) owned secondary schools in South East Nigeria, which consists of Anambra, Ebonyi, Enugu, Abia, and Imo State. The sample size for this study consists of 1200 senior secondary II in-school adolescents.

This sample was drawn using a multi-stage sampling technique. First, the area was stratified into five strata: Abia, Anambra, Ebonyi, Enugu and Imo states respectively. However, the researcher randomly selected three states from the strata Ebonyi, Anambra and Enugu. From each of the States randomly selected, one education zone was randomly selected, and in each education zone, two local government areas were also randomly selected. Again, from each of the randomly selected local governments, two secondary schools were selected randomly making it a total of four secondary schools from the two local governments. This gave a total of four secondary schools from each of the states selected and a total of twelve secondary schools from the three states randomly selected. Thus, from each of the selected schools hundred SS2 were selected thereby giving a total sample of 1,200 students.

The instruments for data collection were four. The instruments are Parenting Style Questionnaire (PSQ) and Sexual Behaviour Questionnaire (SBQ). Parenting style Questionnaire (PSQ) is made up of two sections, A and B. A sought information from the respondents on their personal data. Section $B$ part contained 53 items of four clusters of A-authoritarian, B-authoritative, C-permissive, and D-neglectful with response mode of strongly Agree (SA) 4, Agree (A) 3, disagree (D) 2, and Strongly Disagree (SA) 1. Sexual Behaviour Questionnaire (SBQ) containing 20 items on sexual behaviours with four-point response format of strongly Agree (SA), Agree (A), Disagree (D) and strongly Disagree (SD) weighted 4, 3, 2 and 1 respectively.

The instrument was face validated by three experts, two from the Department of Educational Foundations, and one from the Department of Science Education (Measurement and Evaluation Unit) all from the Faculty of Education, University of Nigeria, Nsukka. To determine the reliability of the instrument, internal consistency reliability was conducted using 30 in-school adolescents from senior secondary school II in Makurdi in Benue State Nigeria. Internal consistency reliability was calculated using the Cronbach alpha correlation coefficient. The analysis of the data yielded reliability coefficient indices of 0.66 and 0.78 for the instruments respectively. Copies of the instruments were administered to the respondents using the direct delivery and retrieval method. The distribution of the questionnaire to the sampled students was done personally by the researcher with the help of two research assistants. Mean scores and standard deviation were used to analyze research questions 1 and 2 while Pearson Product Moment Correlation Coefficient was used to answer the research question 3. Regression analyses were used to test hypotheses 1.

Findings revealed that Authoritative and Authoritarian Parenting styles are the parenting styles for In-school Adolescents in South-East, Nigeria. The constituents of sexual behaviours were established. However, there existed a direct positive relationship 
between parenting styles and sexual behaviour of adolescents but parenting style has no significant relationship with the sexual behaviour of in-school adolescents. There exists a direct positive relationship between Parent Styles and Sexual Behaviour of Adolescents. The inference drawn was that parenting style has no significant relationship with the sexual behaviour of in-school adolescents in South-East Nigeria.

In line with the findings of the study, the educational implications of the findings were highlighted and the recommendations were equally made among others that: Parents should improve on their parenting style may be by openly criticizing their children when their behaviour does not meet their expectations always. Also, Parents should be ready to listen and consider their children opinions when plans are made for the family. The time in-school adolescents spend with peers and friends on Facebook should be reduced. In-school adolescents should abstain from keeping sexual relationships and should desist from attaining night club. Adolescents should stop watching pornographic films. Government should ensure that the school environment becomes friendly. The schools should be operated on very strict rules and regulations. Schools' administration should work with guidance and counseling units and organize seminars and workshops on how to sensitize and curtail sexual behavior of in-school adolescents.

\section{Conflict of Interest Statement}

The authors declare no conflicts of interest.

\section{About the Authors}

Chigbu, Eberechukwu Francisca occupied a position of Lecturer II with PhD in Guidance and Counselling with research interests in counselling psychology and behavioural problems.

Ofojebe, Edna Nkechi occupied a position of Lecturer II with PhD in Guidance and Counselling with a research interest on general issues in interpersonal relationships, adolescents' problems/issues, behavioural problems, delinquent issues among others.

Nnadi, Chinyere Grace occupied a position Lecturer II with $\mathrm{PhD}$ in Guidance and Counselling with research interest on adolescent and parental behavioural problems.

Uzoekwe, H. E. occupied a position as a senior Lecturer with $\mathrm{PhD}$ in Guidance and Counselling with research interests on behavioural problems, educational problems and family issues.

Mokwelu, Blessing Obianuju occupied a position as a Lecturer II with PhD in Guidance and Counselling with research interests on interpersonal relationships and behavioural problems. 


\section{References}

Ann, B., Kofi, A., Asare, G., \& Akinrinola, B. (2004). Role of parents in adolescent sexual activity and contraceptive use in four African countries. Retrieved from https://www.guttmacher.org/pibs/journals/3507209.pdf, Retrieved 18/5/15.

Baumrind, D., \& Hetherington, E. M. (1991). The influence of parenting style on adolescent competence and substance use. Journal of Early Adolescent transition., 236-309.

Berk, H., Rawlings, L., \& Williams, S. (2000). Review the Development of infancy. Retrieved from

https://books.google.com.ng/books?id=CIE.https://books.google.com.ng/books?i $\mathrm{d}=\mathrm{ciBbBAA}$.

Beth, A. K., Anne, S., F., R., Kim, S., \& Miller, S. (2001). Adolescent Sexual Risk behaviour. A multi-system perspective. Retrieved from www.collumber.edu/cu/psychology/courses/3615/readings/kotchick-2001.pdf.

Cherie, A., \& Berhanie, Y. (2015). Assessment of parenting practices and styles and adolescence sexual behaviour among high school Adolescents in Addis Adaba, Ethiopia. Retrieved from $\quad$ https://www.researchgate.net/publication/27683896-Assessment-ofParenting-Practice-and-Style-and-Adolescent-Sexual-Behavior-among-HighSchool-Adolescents-in-Adolesecents-in-Addis-Adaba-Ethiopia

Spera, C. (2005). A review of the relationship among parenting practices, parenting styles, and adolescent school achievement'. Educational Psychology Review. 17 (12): 125-146. doi:10.1007/s10648-005-3950-1

Coleman, L., \& Carter, S. (2005). Underage 'binge' drinking: A qualitative Study into motivations and outcomes. 12 (2) 125-136. Retrieved from https://citeseerx.ist.psu.edu/viewdoc/download?doi=10.1.1.1079.5270\&rep1\&type $=\mathrm{pdf}$

Crow, S. (2008). Suicidal behaviour in adolescents: relationship to weight status, weight control behaviour, and body dissatisfaction. Google Books result. Retrieved from https://pubmed.ncbi.nlm.nih.gov/17922538/

Dinorah, G. T. (2015). Relationship between parenting styles and sexual risk behaviour in Adolescent. Journal of medical institute for sexual health relationship behaviour. $1(2), 56-65$.

Farex, M. (2002). Who is an adolescence. OluAkin Publishers, Ibadan.

Gebhard, P. H. (1982). Sexuality in cross-cultural perspective. Human sexuality, (pp. 121-122). American Psychiatric Association.

Honby, G. (2000). Improving Parental Involvement. Continuum. Retrieved from https://www.researchgate.net/publication/259444945-improving-parentalinvovement 
Huebner, E. S., Drane, W., \& Valois, R. F. (2000). Levels and demographic correlates of adolescent life satisfaction reports. School Psychology International, 21(3), 281292. Retrieved from https://doi.org/10.1177/0143034300213005

Kasier, M. (2003). National survey of adolescents and young Adults: sexual health knowledge, attitudes and experiences. Retrieved from https://khn.org/morningbreakout/dr00017800/

Kathy, N., Lynda, H., Dashiff, C., \& Susan, D. (2002). Relationship between parenting styles and unhealthy sexual behaviour in Adolescent United State. Retrieved from www.revistas.usp.br/riae/viewfile/16930/18-735. Retrieved 10/10/15.

Kelly, P. (2001). Youth at risk: Processes of individualization and responsibisation in the risk society. Studies in the Cultural Politics of Education. 22(1), 23-33. Retrieved from https://doi.org/10.1080/01596300120039731

Kristan, A. M., \& Kaisim, M. (2002). Preventing Risky-sex and adolescent parenthood. Journal of Human Science. 1(2). 23-34.

Levay, V. (2003). the impact of television viewing in influencing Adolescents sexual behaviour. Adolescent sexuality. 3(2), 34-45.

Luberman, L. D. (2006). Eaely predictors of sexual behaviour: implications for young adolescents and their parents. Journal of perspectives on sexual and reproductive health. 38(2):11-44. Retrieved from https://www.researchgate.net/publication/7011763-EarlyPredictors-of-Sexual-Behaviour-Implication-For-Young-Adolescents-For-YoungAdolescents-and-Their-Parents

Maccobay, E. E., \& Martin, J. A. (1983). Socialization in the content of the family child psychology. Child Psychology, 4.(4), 1-101.

Miller, T. (1998). Patterns of Condom Use among adolescents. the impacts of mother adolescents' communication. Retrieved from https://pubmed.ncbi.nlm.nih.gov/9772860

Ncheta, V. (2011). Parenting style among Adolescent in Udi LGA of Enugu State. Enugu State University of Science and technology. Unpublished M.Ed project . Enugu, Enugu.

Nwagbo, C. R., \& Ubachukwu, P. O. (2001). HIV/Aids: History, social implications and coping strategies. Journal of Liberal Studies, 9(1\&2), 279-288.

Omeje, J. C., Millicent, N., Ekwueme, P., \& Omeje, N. (2013). Environmental determinants of risky sexual behaviour. Retrieved from http://www.liste.org/journals/index.php/RHSS/article/viefile/7943/7951.

Onuiwu, U., \& Echefuna, M. (2004). Sexual activities of adolescent in Enugu State. Unpublished B.Ed thesis at Enugu State University. Enugu, Nigeria.

Onyia, U. (2000). Factors associated with sexual behaviour of adolescent of adolescent students in Ezeagu Local Government Area. Unpublished M.Ed thesis, Enugu State University of Science and Technology.

Oracle, M. (2012). Adolescent males aggressive sexual behaviour. International Journal of Social sciences. 3(1):34-39. 
Oriade, M. J. (2012). Correlates of Adolescent sexual behaviour in Bassa Education Zone Kogi State. Implication for counseling. International Journal of Social sciences. 3(1): 50-65.

Perozzi, E. P. (2007). Examining adolescent drinking and adolescents' perceptions of parenting monitoring, communication and parenting style in a rural setting. Unpublished master's thesis, University of Virginia. U. S. A.

Petard, C., Courtois, R., \& Rusch, E. (2008). The influence of peers on risky sexual behaviour during adolescence. France: University Francois Press. Retrieved from University François Rabelais, Department de psychologie, Tour, Francd. Eurj. Contracept reprod health care 208. sep; B. (3): 264-70doi:10.108.

Ralph, J., Clement, G. M., Wingood, G. M., C., R., Cab, K., Brendak, S., . . Reimid, P. (2014). Parental monitoring: Association with adolescents risk behaviour. Unpublished M.Ed Thesis.

Sieverding, J. A., Adler, N., \& Witts, E. J. (2005). The influence of parental monitoring on adolescent sexual invitation, Arch pediatr Adolescence med. Arch pediatr Adolescence med, 159(8): 7249.

Udoga, H. (2011). Age of sexual debut among Nigeria Adolescents. journal of social and Human sciences. 5(3): 30-45.

Ufobi, U. (2001). Infant and young children. International journal of education. 2(1): 25-33. Umeugokwe, U. (2005). Sexually transmitted diseases information. Integrated Journal of Education and social Science. 1(2): 34-45.

Utobo, N. (2002). Sexual debut among adolescent in South East Nigeria. Unpublished M.Ed Thesis: University of Ibadan. Ibadan, Oyo, Nigeria.

Voon, V., Mole, T. B., Banca, P., Porter, L., Morris, L., Mitchell S. (2014). Neutral correlates of sexual cue reactivity in individuals with and without Compulsive Sexual Behaviour. Retrieved from https://journals.plos.org/plosone/article?id=10.1371/journal.pone.0102419

Winnie, L. (2008). Research into the psychological well-being of young refugees. Board of International Affairs of the Royal College of Psychiatrists 5(3): 60-62. Adolescent. Retrieved from https://www.researchgate.net/publication/322370855-Researchinto-the-psychological-well-being-of-young.

$\begin{array}{ccccc}\text { World Health } & \text { Organisation } & \text { (WHO) } & \text { (2009). Retrieved } & \text { from } \\ \text { http://www.who.int/topics/sexuallytransmittedinfection/en/. } & \end{array}$


Chigbu, Eberechukwu Francisca; Ofojebe, Edna Nkechi;

Grace Chinyere Nnadi; Uzoekwe, H. E.; Mokwelu, Blessing Obianuju

PARENTING STYLES AS DETERMINANT OF SEXUAL BEHAVIOUR

OF IN-SCHOOL ADOLESCENTS IN SOUTH EAST NIGERIA

Creative Commons licensing terms

Author(s) will retain the copyright of their published articles agreeing that a Creative Commons Attribution 4.0 International License (CC BY 4.0) terms will be applied to their work. Under the terms of this license, no permission is required from the author(s) or publisher for members of the community to copy, distribute, transmit or adapt the article content, providing a proper, prominent and unambiguous attribution to the authors in a manner that makes clear that the materials are being reused under permission of a Creative Commons License. Views, opinions and conclusions expressed in this research article are views, opinions and conclusions of the author(s). Open Access Publishing Group and European Journal of Education Studies shall not be responsible or answerable for any loss, damage or liability caused in relation to/arising out of conflicts of interest, copyright violations and inappropriate or inaccurate use of any kind content related or integrated into the research work. All the published works are meeting the Open Access Publishing requirements and can be freely accessed, shared, modified, distributed and used in educational, commercial and non-commercial purposes under a Creative Commons Attribution 4.0 International License (CC BY 4.0). 